\title{
Mentalizing based on external features in borderline personality disorder compared with healthy controls: The role of attachment dimensions and childhood trauma
}

Martijn Van Heel ${ }^{\text {a }}$, Patrick Luyten ${ }^{\text {a,d }}$, Celine De Meulemeester ${ }^{\text {a }}$, Dominique Vanwalleghem ${ }^{\mathrm{c}}$, Rudi Vermote $^{\mathrm{b}}$, and Benedicte Lowyck ${ }^{\mathrm{b}}$

\section{KU Leuven}

Author Note

\footnotetext{
${ }^{a}$ Faculty of Psychology and Educational Sciences, KU Leuven, Leuven, Belgium

${ }^{\mathrm{b}}$ University Psychiatric Hospital UPC KU Leuven, Campus Kortenberg and Department of

Neurosciences, Faculty of Medicine, KU Leuven, Leuven, Belgium

${ }^{\mathrm{c}}$ University Psychiatric Hospital UPC KU Leuven, Campus Kortenberg, Belgium

${ }^{\mathrm{d}}$ Research Department of Clinical, Educational and Health Psychology, University College London, UK.
}

\section{In press: Journal of Personality Disorders}

The authors have no funding to report.

Correspondence concerning this article should be addressed to Martijn Van Heel, Faculty of Psychology and Educational Sciences, KU Leuven, Tiensestraat 102 - box 3722, 3000 Leuven, Belgium. E-mail: martijn.vanheel@kuleuven.be 


\begin{abstract}
Extant research suggests that Borderline Personality Disorder (BPD) is associated with impairments in mentalizing, that is, comprehending behavior in terms of underlying mental states. However, the precise nature of these impairments remains unclear. The literature is mixed concerning mentalizing based on external features of others, and specifically Facial Emotion Recognition (FER) in BPD patients. This study investigated FER differences in 79 BPD patients and 79 matched healthy controls using the Reading the Mind in the Eyes Test (RMET). Furthermore, we investigated attachment dimensions and childhood trauma in relation to mentalizing based on external features. Results showed that BPD patients performed worse on positive and negative emotions. Furthermore, avoidant attachment was negatively related to FER for neutral emotions, particularly in the control group. Trauma was negatively related to FER at trend level, particularly in BPD patients. The implications for our understanding of mentalizing based on external features in BPD are discussed.
\end{abstract}

Keywords: Borderline personality disorder, mentalizing, facial emotion recognition, RMET, attachment 
Mentalizing based on external features of others

Borderline Personality Disorder (BPD) is a common but complex psychiatric disorder associated with severe impairments in interpersonal functioning (Fonagy \& Luyten, 2009, 2016; Skodol et al., 2002). The prevalence of BPD in the United States is estimated to be $6 \%$ (Grant et al., 2008), and BPD has a high comorbidity with mood and anxiety disorders, and other personality disorders, such as narcissistic personality disorder (Grant et al., 2008). About 60$70 \%$ of BPD patients attempt suicide at least once, of which $8-10 \%$ have a lethal outcome (Leichsenring, Leibing, Kruse, New, \& Leweke, 2011; Oldham, 2003).

Current theoretical approaches to BPD emphasize the importance of impairments in social cognition or mentalizing, that is, the capacity to comprehend the behavior of oneself and others in terms of underlying mental states, such as thoughts, feelings, needs, wishes, etc. (Fonagy \& Luyten, 2009; Fonagy, Target, Steele, \& Steele, 1998). Earlier theoretical formulations suggested that BPD was associated with general impairments in mentalizing (Fonagy et al., 1998), while more recent approaches stress that individuals with BPD exhibit marked impairments in some aspects of mentalizing, but not in others (Luyten, Fonagy, Lowyck, \& Vermote, 2012). BPD patients are thought to be particularly sensitive to external features of others, such as facial expressions (Bender \& Skodol, 2007; Blatt \& Auerbach, 1988; Domes et al., 2008; Luyten et al., 2012), but often go far beyond the available evidence in developing a mental model of the inner states of other people, which is expressed in so-called hypermentalizing, that is, excessive mentalizing (Sharp et al., 2011). Studies indeed suggest that BPD patients have difficulties correctly inferring mental states based on internal characteristics of the self and others (Fonagy \& Luyten, 2009; Lieberman, 2007). Research about mentalizing based on external characteristics in BPD, however, has produced mixed results (Bland, Williams, Scharer, \& Manning, 2004; Daros, Zakzanis, \& Ruocco, 2013; Fertuck et al., 2009; 
Mentalizing based on external features of others

Levine, Marziali, \& Hood, 1997; Meyer, Pilkonis, \& Beevers, 2004; Minzenberg, Poole, \& Vinogradov, 2006; Murphy, 2006; Wagner \& Linehan, 1999). While some studies found improved emotion recognition in BPD patients compared with control participants (Fertuck et al., 2009; Wagner \& Linehan, 1999), other studies report no differences between BPD patients and matched controls (Lowyck et al., 2016; Meyer et al., 2004; Murphy, 2006). Still other studies suggest BPD patients may show a deficit in emotion recognition. This deficit has been observed in the recognition of basic emotions such as sadness, fear, and anger, as well as in more complex emotions such as jealousy and regret (e.g., Minzenberg et al., 2006).

These inconsistent findings may be at least partly explained by methodological differences between studies. First, research in this area has often been conducted in samples with BPD features, and not always in clinical samples of BPD patients. Second, studies in this area have often only investigated basic emotions (e.g., anger, fear, and happiness). Although research on basic emotions is very important, emotions in daily interactions are typically more complex in nature. This is particularly true of emotions that are highly prevalent in BPD patients, such as jealousy and regret. Furthermore, we currently know very little about potential predictors of mentalizing with regard to externally based features in BPD (Ghiassi, Dimaggio, \& Brüne, 2010; Pollak, Cicchetti, Hornung, \& Reed, 2000). The literature on BPD and mentalizing suggests two related concepts could be very important in explaining mentalizing in BPD, namely attachment and childhood trauma.

Studies suggest that BPD patients often show anxious and disorganized attachment patterns (Fonagy \& Luyten, 2016; Levy, Meehan, Weber, Reynoso, \& Clarkin, 2005), both of which have been hypothesized to influence mentalizing (Skodol, Gunderson, et al., 2002). Individuals with high levels of attachment anxiety, because of their hypersensitivity to rejection 
Mentalizing based on external features of others

and abandonment, have often also developed a hypersensitivity to external features in others, including affective facial expressions (Mikulincer \& Shaver, 2007; 2008). Individuals high on attachment avoidance, by contrast, are often particularly poor at "reading" facial expression in others because of their tendency to deactivate attachment needs and concerns.

Studies on the influence of trauma on facial emotion expression have yielded somewhat mixed results (Brüne, Walden, Edel, \& Dimaggio, 2016; Fertuck et al., 2009; Lowyck et al., 2016; Pears \& Fisher, 2005). This may not be surprising. On the one hand, hypersensitivity to mental states may be a reaction to traumatic experiences as an attempt to search for early signs of impending threat. However, particularly when trauma is severe, individuals may defensively inhibit mentalizing, as thinking about the intentions of others may become too threatening, leading to hyposensitivity to mental states (Brüne et al., 2016). Research has shown that childhood abuse, for instance, is related to difficulties in emotion recognition later in life, even after controlling for the effects of age, intelligence, and executive functioning (Pears \& Fisher, 2005). Lowyck et al. (2016), in turn, using a morphing paradigm, found that difficulties in emotion recognition in BPD patients were mainly present in patients with a trauma history. However, Fertuck et al. (2009), using the Reading the Mind in the Eyes Test (RMET), found that trauma history was not associated with emotion recognition in a sample of BPD patients. Yet, in another study using the RMET, BPD patients were significantly better and faster in mental state discrimination (Frick et al., 2012). It is clear that more research in this area is needed to disentangle the roles of BPD status, attachment, and childhood trauma in facial emotion recognition in BPD patients. 
Mentalizing based on external features of others

\section{The Present Study}

The aim of the present study was to investigate potential differences between BPD patients and matched controls in the accuracy of emotion recognition as assessed with the RMET. Furthermore, this study investigated the role of attachment and childhood trauma as possible predictors of emotion recognition in BPD patients. Based on previous research, summarized above, the following three hypotheses were tested.

First, we expected there to be no differences in the recognition of negative emotions between BPD patients and normal controls, as BPD patients have been shown to be at least as sensitive to recognizing negative emotions as normal controls. However, based on studies showing a negative interpretation bias in BPD patients, we expected BPD patients to be less accurate than matched controls regarding neutral and positive emotions.

Second, concerning trauma and attachment, normal controls typically have relatively low scores on attachment anxiety and trauma, we expected both attachment anxiety and childhood trauma to be positively related to facial emotion recognition in this group. As noted, low levels of attachment anxiety and trauma in this group could be associated with a hypersensitivity to emotional states in others, which may be expressed as superior emotion recognition (Sharp et al., 2011). In BPD patients with childhood trauma, however, adverse experiences are typically more severe and are therefore more likely to be associated with a defensive inhibition of mentalizing (Fonagy \& Bateman, 2008). This may also be true for attachment anxiety in BPD patients, as high attachment anxiety may be associated with a tendency to overinterpret facial emotional displays in others.

Finally, concerning attachment avoidance, we expected similar effects in both BPD patients and controls. Indeed, as noted, attachment avoidance is generally associated with the 
Mentalizing based on external features of others

downplaying of emotions and relationships (Mikulincer \& Shaver, 2007) and should thus be negatively associated with emotion recognition in both samples.

\section{Methods}

\section{Participants and Procedure}

The BPD sample consisted of consecutively admitted patients at the University psychiatric hospital UPC KU Leuven, Kortenberg, Belgium, who fulfilled the following inclusion criteria: (a) a primary diagnosis of BPD according to the Structured Clinical Interview for DSM-IV Axis II Disorders (SCID-II), (b) age between 18 and 60 years, and (c) Dutch literacy. A total of 79 patients agreed to participate and were enrolled in the study; 58 were women and 21 men, with an average age of 28.34 years $(S D=9.41$; range 18-59). One participant had completed primary school, 16 middle school, 41 high school and 21 received higher education. After signing an informed consent, participants received a pack of questionnaires (see below) and an appointment was scheduled for the emotion recognition task.

Participants in the control sample were recruited from the community based on the characteristics of the BPD group (i.e., gender, age, and level of education) by a research assistant. The control participants were recruited through flyers posted in university buildings, hospitals, and community organizations. They were matched with the BPD patients on gender, age, and level of education, and were screened for the absence of personality disorder using the Assessment of DSM-IV Personality Disorders (ADP-IV), a screening tool for personality pathology (see below). The average age of the control participants (58 females, 21 males) was 28.29 years $(S D=9.41$; range $17-58)$. One participant had completed primary school, 12 middle school, 43 high school and 23 received higher education. The control participants received $€ 25$ for their participation. The testing of the BPD population and the control participants took place 
Mentalizing based on external features of others

in similar settings at the university hospital and the Faculty of Psychology and Educational Sciences, KU Leuven (Leuven, Belgium), respectively.

\section{Measures}

The SCID-II interview (First, Gibbon, Spitzer, Williams, \& Benjamin, 1997), which consists of 119 questions, assesses ten DSM-IV personality disorders (paranoid, borderline, narcissistic, schizoid, schizotypal, antisocial, histrionic, avoidant, dependent, and obsessivecompulsive), as well as two personality disorders listed in the DSM-IV for research purposes (depressive, passive-aggressive). Two residents in psychiatry were trained in administering the SCID-II by a senior research psychologist. Training involved sessions learning the SCID-II structure, observing the senior psychologist interviewing three patients, and joint administration of the SCID-II to five patients followed by a discussion of scores with the trainer afterwards, and supervision of several cases until sufficient reliability was achieved.

As noted, in the normal control group, the $A D P-I V$ (Schotte, de Doncker, Vankerckhoven, Vertommen, \& Cosyns, 1998) was administered to screen for personality disorder. The ADP-IV is a personality disorder screening tool consisting of 94 items that represent the 80 criteria of the 10 DSM-IV personality disorders and the 14 research criteria of the depressive and passiveaggressive personality disorders in a randomized order. Each DSM-IV item is scored on a sevenpoint trait scale, ranging from 1 (totally disagree) to 7 (totally agree). The ADP-IV allows for both dimensional and categorical scoring formats. Categorical personality disorder diagnoses are obtained according to the DSM-IV thresholds. In this study, the categorical scoring format was used, and subjects were not included in the study when they scored above the respective DSMIV thresholds. Based on these results, three control participants were excluded. The ADP-IV was administered only in the control group. 
Mentalizing based on external features of others

The Childhood Trauma Questionnaire (CTQ; Bernstein, Ahluvalia, Pogge, \& Handelsman, 1997) is a 25-item self-report inventory that assesses early adverse experiences before the age of 18 years. The CTQ consists of five subscales-emotional abuse, emotional neglect, sexual abuse, physical abuse, and physical neglect — as well as a total score. The cut-off scores of the CTQ are 13 or higher for emotional abuse, 10 or higher for physical abuse, 8 or higher for sexual abuse, 15 or higher for emotional neglect, and 10 or higher for physical neglect. Each item is scored on a five-point Likert scale, ranging from 1 (never true) to 7 (very often true). The CTQ has demonstrated good levels of internal reliability and criterion-related validity (Bernstein et al., 1997). The CTQ was administered in both the BPD group $(\alpha=.935)$ and the normal controls $(\alpha=.891)$.

The Experiences in Close Relationships-Revised (ECR-R; Fraley, Waller, \& Brennan, 2000) is a questionnaire that consists of 36 items measuring attachment anxiety and attachment avoidance. Items are scored on a seven-point Likert scale from 1 (strongly disagree) to 7 (strongly agree). This questionnaire was translated into Dutch by Buysse and Dewitte (2004). The ECR-R was administered in both the BPD patient $(\alpha=.906)$ and control $(\alpha=.909)$ groups.

The RMET (Baron-Cohen, Wheelwright, Hill, Raste, \& Plumb, 2001) consists of 36 black-and-white pictures of different faces (18 male and 18 female) of which only the eyes and the region around them is visible. In the four corners of each picture, a description of a possible emotion or mental state is printed. Only one of these four descriptions is accurate; the other three are incorrect distractors (See Figure 1). A glossary of the emotions is also included to make sure that all the descriptions of emotions are clear for all participants. In this study, besides a total score, separate scores for positive emotions (9 items) (e.g., “amused"), neutral emotions (17 items) (e.g., "baffled"), and negative emotions (10 items) (e.g., "irritated") were calculated 
Mentalizing based on external features of others

following Scott, Levy, Adams, and Stevenson (2011). The RMET was administered in both the BPD patient and control groups.

\section{Statistical Analyses}

Independent $t$-tests were used to investigate differences in the RMET scores between the two groups. Three multiple linear regression analyses were conducted to investigate the predictive value of childhood trauma, attachment anxiety, and attachment avoidance on the RMET scores. In each of the three regression analyses group status (BPD versus control) was included, as well as the interaction between group status and the respective predictor. Cohen's $d$ was used as an indication of effect sizes. According to Cohen (1988), $d=0.2$ is indicative of a small effect size, $d=0.5$ a medium effect size, and $d=0.8$ a large effect size.

\section{Results}

\section{Comparisons between BPD and Control on RMET}

The control group was significantly more accurate on the total RMET. Likewise, they were more accurate in recognizing positive emotions. They also tended to be more accurate in recognizing negative emotions, but this trend failed to reach significance. Finally, and somewhat surprising, there was no difference concerning the recognition of neutral emotions. (see Table 1 and Figure 2). Effect sizes, however, were small to medium for all comparisons.

\section{Predictors of Facial Emotion Recognition}

As expected, BPD patients had significantly higher scores on the CTQ than normal controls. Similarly, BPD patients had significantly higher scores on both attachment anxiety and attachment avoidance than matched controls (see Table 2).

There was a trend toward an interaction between group status and trauma for neutral emotions, but this trend did not reach significance. As Figure 3 shows, as expected, emotion 
Mentalizing based on external features of others

recognition was better in both the BPD patients and healthy controls for individuals with low levels of trauma. At higher levels of trauma, accuracy of facial emotion recognition decreased, particularly in controls. For negative and positive emotions, as well as the total score, none of the variables included in the regression analysis was significant. Results are displayed in Table 3, Table 4, and Table 5.

For anxious attachment, group status was a significant predictor for negative emotions and a predictor at trend level for the total score, suggesting that normal controls were significantly better at recognizing negative and overall emotions. Yet, neither attachment anxiety nor the interaction between attachment anxiety and group status predicted emotion recognition. Results are displayed in Table 4. Concerning avoidant attachment, group status interacted significantly with avoidant attachment to predict the recognition of neutral emotions (see Figure 4). This interaction indicates that high attachment avoidance was associated with worse facial neutral emotion recognition, but this effect was observed only in the control group. However, attachment avoidance or the interaction between attachment avoidance and group did not predict emotion recognition of negative and positive emotions, nor of the RMET total score. Results are displayed in Table 5.

\section{Discussion}

In this study, we compared externally based mentalizing between BPD patients and matched control participants using the RMET. Furthermore, we investigated whether childhood trauma and the attachment dimensions of anxiety and avoidance were associated with externally based mentalizing in this task.

A first aim was to investigate differences in externally based mentalizing capacity between BPD patients and healthy controls. Our results show that BPD patients are overall less 
Mentalizing based on external features of others

accurate in mentalizing complex emotions of the other in comparison with matched control participants, when only the eye region of the other is available. This is an important restriction given that the typical mentalizing profile in BPD patients focuses on external features in others (Fonagy \& Luyten, 2009). This worse recognition is primarily reflected in less accurate recognition of positive (e.g., happiness) and negative (e.g., anger) emotions (Scott et al., 2011), with small to medium effect sizes in the BPD group compared with the control group. There was no significant difference between the two groups for neutral emotions. These findings concerning somewhat more complex emotions as assessed by the RMET complement the results of a number of meta-analyses, which suggest that BPD patients are also worse at recognizing neutral and positive basic emotions (Domes, Schulze, \& Herpertz, 2009; Herpertz \& Bertsch, 2014; Mitchell \& Dickens, 2014). However, other studies using the RMET have shown different results. Fertuck et al. (2009), for instance, reported that BPD patients performed better on the RMET than normal controls.

A second aim was the assessment of the predictive value of attachment and childhood trauma on externally based mentalizing in the RMET. Childhood trauma and attachment were not significantly related to mentalizing, with two exceptions. First, childhood trauma was negatively related at a trend level to accuracy of recognition of neutral emotions in both the BPD group and the control group. However, the influence of trauma was stronger in the control group. This is consistent with the findings of Lowyck et al. (2016) that difficulties in mentalizing are mainly present in patients who experienced a trauma during their childhood. However, other studies found no influence (Fertuck et al., 2009), or even a positive influence (Frick et al., 2012) from childhood trauma on mentalizing. It is possible that the severity and/or nature of childhood trauma is a crucial factor in determining its influence. Particularly severe trauma may negatively 
Mentalizing based on external features of others

influence recognition of facial emotions (Brüne et al., 2016). More research is needed to clarify the influence of childhood trauma on the capacity to mentalize. Second, an interaction between group status and avoidant attachment was significantly negatively related to the accuracy of recognition of neutral emotions, particularly in the control group. This is consistent with findings that individuals with high avoidant attachment are often poor at recognizing facial emotions, since they tend to deactivate attachment needs and concerns (Fonagy \& Bateman, 2008). However, it is surprising that the effect was primarily observed in the group of healthy participants. More research is needed to further clarify this finding.

\section{Limitations}

Despite the strength of this study, there are also a few limitations. First, the CTQ is a selfreport measure; the participants' trauma scores are potentially distorted by recall and reporting bias. Second, the RMET is limited to assessing static emotions, which compromises the ecological validity of the present study. Lowyck et al. (2016) used dynamically changing facial expressions to assess emotion recognition. Their findings also showed that BPD patients were less accurate when the emotions were fully expressed, however, there was no evidence for a general emotion-recognition deficit. There is evidence in a sample with autism spectrum disorder that dynamic representations of emotions show little difference with static representations (Enticott et al., 2013), which suggests that findings from both representations could be very similar. Third, comorbidity or symptom severity may have influenced BPD patients' emotion recognition, given the heterogeneous nature of the disorder. For instance, there is evidence that depression or anxiety are associated with impaired emotion recognition (Demenescu, Kortekaas, den Boer, \& Aleman, 2010). However, comorbid disorders are not crucial to the diagnosis of BPD and the focus of the present study was on the associations between mentalizing and 
Mentalizing based on external features of others

attachment and trauma history, respectively. Fourth, medication usage in the BPD group was not taken account in this study. However, previous research in a similar sample indicated that medication did not influence the mentalizing capacity of BPD patients (Lowyck et al., 2016). Fifth, the participants were tested in a calm and static environment. The low level of arousal of the testing environment could be a possible explanation for the relatively small between-group differences. The literature suggests that arousal may inhibit controlled mentalizing after a certain threshold is reached and that said threshold is lower for BPD patients (Fonagy \& Luyten, 2009). This also means that the performance of BPD can change across different contexts. For instance, Farina et al. (2014) found that BPD patients showed reduced brain connectivity when confronted with specific attachment-related memories, whereas this reduction was not observed when confronted with general autobiographical memories, which could account for the state dependent mentalizing capacity. The measures in the present study did not elicit specific, possible traumatic, memories, which may mean that the cognitive demand for BPD patients is limited. This also means that it is possible that the disruptive effects on emotion recognition, related to this cognitive load, do not occur in the present study.

With regard to implications for clinical practice, this study supports the idea that BPD patients are indeed capable of recognizing emotions when their arousal is not too high. This population could benefit from learning to manage their arousal and to learn more about emotions. 
Mentalizing based on external features of others

\section{References}

Baron-Cohen, S., Wheelwright, S., Hill, J., Raste, Y., \& Plumb, I. (2001). The "Reading the Mind in the Eyes" Test revised version: A study with normal adults, and adults with Asperger syndrome of high-functioning autism. Journal of Child Psychology and Psychiatry and Allied Disciplines, 42, 241-251. doi: 10.1111/1469-7610.00715

Bender, D.S., \& Skodol, A.E. (2007). Borderline personality as a self-other representational disturbance. Journal of Personality Disorders, 21, 500-517. doi: 10.1521/pedi.2007.21.5.500

Bernstein, D. P., \& Fink, L. (1998). Childhood Trauma Questionnaire: A retrospective self-report (CTQ). San Antonio, TX: Pearson Inc.

Bernstein, D.P., Ahluvalia, T., Pogge, D., \& Handelsman, L. (1997). Validity of the Childhood Trauma Questionnaire in an adolescent psychiatric population. Journal of the American Academy of Child and Adolescent Psychiatry, 36(3), 340-348.

Bland, A. R., Williams, C. A., Scharer, K., \& Manning, S. (2004). Emotion processing in borderline personality disorders. Issues in Mental Health Nursing, 25, 655-672. doi: $10.1080 / 01612840490486692$

Blatt, S.J., \& Auerbach, J.S. (1988). Differential cognitive disturbances in three types of borderline patients. Journal of Personality Disorders, 2, 198-211. doi: 10.1521/pedi.1988.2.3.198

Brüne, M., Walden, S., Edel, M.A., \& Dimaggio, G. (2016). Mentalization of complex emotions in borderline personality disorder: The impact of parenting and exposure to trauma on the performance in a novel cartoon-based task. Comprehensive Psychiatry, 64, 29-37. doi: 10.1016/j.comppsych.2015.08.003 
Mentalizing based on external features of others

Buysse, A., \& Dewitte, M. (2004). Nederlandse vertaling van de Experiences in Close Relationships Scale-revised. Unpublished manuscript, Ghent University, Ghent, Belgium.

Cohen, J. (1988). Statistical power analysis for the behavioral sciences (2nd ed.). Hillsdale, NJ: Erlbaum.

Daros A.R., Zakzanis K.K., Ruocco A.C. (2013). Facial emotion recognition in borderline personality disorder. Psychological Medicine, 43, 1953-1963. doi: $10.1017 / \mathrm{S} 0033291712002607$

Demenescu, L.R., Kortekaas, R., den Boer, J.A., \& Aleman, A. (2010). Impaired attribution of emotion to facial expressions in anxiety and major depression. PLoS One, 5, e15058. doi: 10.1371/journal.pone.0015058

Domes, G., Czieschnek, D., Weidler, F., Berger, C., Fast, K., \& Herpertz, S. C. (2008). Recognition of facial affect in borderline personality disorder. Journal of Personality Disorders, 22, 135-147. doi: 10.1521/pedi.2008.22.2.135

Domes, G., Schulze, L., \& Herpertz, S.C. (2009). Emotion recognition in borderline personality disorder - A review of the literature. Journal of Personality Disorders, 23, 6-19.

Enticott, P.G., Kennedy, H.A., Johnston, P.J., Rinehart, N.J., Tonge, B.J., Taffe, J.R., \& Fitzgerald, P.B. (2014) Emotion recognition of static and dynamic faces in autism spectrum disorder. Cognition and Emotion, 28(6), 1-21. doi: $10.1080 / 02699931.2013 .867832$

Farina, B., Speranza, A.M., Dittoni, S., Gnoni, V., Trentini, C., Maggiora, C., . . ., \& Della Marca, G. (2014). Memories of attachment hamper EEG cortical connectivity in dissociative patients. European Archives of Psychiatry and Clinical Neuroscience, 1-10. doi: $10.1007 / \mathrm{s} 00406-013-0461-9$ 
Mentalizing based on external features of others

Fertuck, E.A., Jekal, A., Song, I., Wyman, B., Morris, M.C., Wilson, S.T., . .., \& Stanley, B. (2009). Enhanced 'Reading the Mind in the Eyes' in borderline personality disorder compared to healthy controls. Psychological Medicine, 39, 1979-1988. doi: $10.1017 / \mathrm{S} 003329170900600 \mathrm{X}$

First, M.B., Spitzer, R.L., Gibbon, M., Williams, J.B., \& Benjamin, L.S. (1997). Structured clinical interview for DSM-IV Axis II personality disorders (SCID-II). Washington, DC: American Psychiatric Press.

Fonagy, P., \& Bateman, A. (2008). The development of borderline personality disorder: A mentalizing model. Journal of Personality Disorders, 22, 4-21. doi: 10.1521/pedi.2008.22.1.4

Fonagy, P., \& Luyten, P. (2009). A developmental, mentalization-based approach to the understanding and treatment of borderline personality disorder. Development and Psychopathology, 21, 1355-1381. doi: 10.1017/S0954579409990198

Fonagy, P., \& Luyten, P. (2016). A multilevel perspective on the development of borderline personality disorder. In D. Cicchetti (Ed.), Developmental Psychopathology. Vol. 3: Risk, disorder, and adaptation (3rd ed, pp. 727-792). New York, NY: Wiley.

Fonagy, P., Target, M., Steele, H., \& Steele, M. (1998). Reflective-functioning manual, Version 5 , for application to Adult Attachment Interviews. Unpublished manuscript, University College London, London, UK.

Fraley, R.C., Waller, N.G., \& Brennan, K.A. (2000). An item response theory analysis of selfreport measures of adult attachment. Journal of Personality and Social Psychology, 78, 350-365. doi: 10.1037/0022-3514.78.2.350

Frick, C., Lang, S., Kotchoubey, B., Sieswerda, S., Dinu-Biringer, R., Berger, M., . . Barnow, S. 
Mentalizing based on external features of others

(2012) Hypersensitivity in borderline personality disorder during mindreading. PLoS ONE, 7, e41650. doi:10.1371/journal.pone.0041650

Ghiassi, V., Dimaggio, G., \& Brüne, M. (2010). Dysfunctions in understanding other minds in borderline personality disorder: A study using cartoon picture stories. Psychotherapy Research, 20, 657-667. doi: 10.1080/10503307.2010.501040

Grant, B.F., Chou, S.P., Goldstein, R.B., Huang, B., Stinson, F.S., Saha, T.D., . . Ruan, W.J. (2008). Prevalence, correlates, disability, and comorbidity of DSM-IV borderline personality disorder: Results from the Wave 2 National Epidemiologic Survey on Alcohol and Related Conditions. Journal of Clinical Psychiatry, 69, 533-545.

Herpertz, S.C. \& Bertsch, K. (2014). The social-cognitive basis of personality disorders. Current Opinion in Psychology, 27, 73-77. doi: 10.1097/YCO.00000000000000260951-7367

Leichsenring, F., Leibing, E., Kruse, J., New, A., \& Leweke F. (2011). Borderline personality disorder. Lancet, 377, 74-84. doi: 10.1016/S0140-6736(10)61422-5

Levine, D., Marziali, E., \& Hood, J. (1997). Emotion processing in borderline personality disorders. Journal of Nervous and Mental Disease, 185, 240-246.

Levy, K.N., Meehan, K.B., Weber, M., Reynoso, J., \& Clarkin, J.F. (2005). Attachment and borderline personality disorder: Implications for psychotherapy. Psychopathology, 38, 64-74. doi: 10.1159/000084813

Lieberman, M.D. (2007). Social cognitive neuroscience: A review of core processes. Annual Review of Psychology, 58, 59-89. doi: 10.1146/annurev.psych.58.110405.085654

Lowyck, B., Luyten, P., Vanwalleghem, D., Vermote, R., Mayes, L.C., \& Crowley, M.J. (2016). What's in a face? Mentalizing in borderline personality disorder based on dynamically changing facial expressions. Personality Disorders: Theory, Research and Treatment, 7, 
Mentalizing based on external features of others

72-79. doi: $10.1037 /$ per0000144

Luyten, P., Fonagy, P., Lowyck, B., \& Vermote, R. (2012). Assessment of mentalization. In A. Bateman \& P. Fonagy (Eds.), Handbook of mentalizing in mental health practice (pp. 4365). Washington, DC: American Psychiatric Publishing.

Meyer, B., Pilkonis, P. A., \& Beevers, C.G. (2004). What's in a (neutral) face? Personality disorders, attachment styles and the appraisal of ambiguous social cues. Journal of Personality Disorder, 18, 320-336. doi: 10.1521/pedi.2004.18.4.320

Mikulincer, M., \& Shaver, P.R. (2007). Attachment in adulthood: Structure, dynamics, and change. New York, NY: Guilford Press.

Mikulincer, M. \& Shaver, P.R. (2008). Adult attachment and affect regulation. In J. Cassidy \& P. R. Shaver (Eds.), Handbook of attachment: Theory, research, and clinical applications (2nd ed., pp. 503-531). New York, NY: Guilford Press.

Minzenberg, M.J., Poole, J.H., \& Vinogradov, S. (2006). Social-emotion recognition in borderline personality disorder. Comprehensive Psychiatry, 47, 468-474. doi: 10.1016/j.comppsych.2006.03.005

Mitchell, A.E. \& Dickens, G. L. (2014). Facial emotion processing n borderline personality disorder: A systematic review and meta-analysis. Neuropsychology Review, 24, 166-184. doi: 10.1007/s11065-014-9254-9

Murphy, D. (2006). Theory of mind in Asperger's syndrome, schizophrenia and personality disordered forensic patients. Cognitive Neuropsychology, 11, 99-111.

Oldham, J.M. (2003). Borderline personality and suicidality. American Journal of Psychiatry, 163, 20-26. doi: 10.1146/annurev.clinpsy.032408.153457

Pears, K.C., \& Fisher, P.A. (2005). Emotion understanding and theory of mind among maltreated 
Mentalizing based on external features of others

children in foster care: Evidence of deficits. Development and Psychopathology, 17, 4765. doi: 10.1017/S0954579405050030

Pollak, S.D., Cicchetti, D., Hornung, K., \& Reed, A. (2000). Recognizing emotions in faces: Developmental effects of child abuse and neglect. Developmental Psychology, 36, 679688. doi: 10.1037/0012-1649.36.5.679

Schotte, C.K.W., de Doncker, D., Vankerckhoven, C., Vertommen, H., \& Cosyns, P. (1998). Selfreport assessment of the DSM-IV personality disorders. Measurement of trait and distress characteristics: The ADP-IV. Psychological Medicine, 28, 1179-1188.

Scott, L.N., Levy, K.N., Adams, R.B., \& Stevenson, M.T. (2011). Mental state decoding abilities in young adults with borderline personality disorder traits. Personality Disorders: Theory, Research, and Treatment, 2, 98-112. doi: 10.1037/a0020011

Sharp, C., Pane, H., Ha, C., Venta, A., Patel, A. B., Sturek, J., \& Fonagy, P. (2011). Theory of mind and emotion regulation difficulties in adolescents with borderline traits. Journal of the American Academy of Child and Adolescent Psychiatry, 50, 563-573. doi: 10.1016/j.jaac.2011.01.017

Skodol, A.E., Gunderson, J.G., Pfohl, B., Widiger, T.A., Livesley, W.J., \& Siever, L J. (2002). The borderline diagnosis I: Psychopathology, comorbidity, and personality structure. Biological Psychiatry, 51, 936-950. doi: 10.1016/S0006-3223(02)01324-0

Skodol, A.E., Siever, L.J., Livesley, W.J., Gunderson, G.J., Pfohl, B., \& Widiger, T.A. (2002). The borderline diagnosis II: Biology, genetics, and clinical course. Biological Psychiatry, 51, 951-963. doi: 10.1016/S0006-3223(02)01325-2

Wagner, A. W., \& Linehan, M. M. (1999). Facial expression recognition ability among women with borderline personality disorder: Implications for emotion regulation? Journal of 
Mentalizing based on external features of others

Personality Disorders, 13, 329-344. doi: 10.1521/pedi.1999.13.4.329 
Mentalizing based on external features of others

Table 1

Comparison of the Proportion of Correct Answers on the Reading the Mind in the Eyes Test between Borderline Personality Disorder (BPD) Patients and Healthy Control Participants

\begin{tabular}{|c|c|c|c|c|c|c|c|}
\hline & \multicolumn{2}{|c|}{$\mathrm{BPD}(n=79)$} & \multicolumn{2}{|c|}{ Healthy controls $(n=79)$} & \multirow[b]{2}{*}{$t$} & \multirow[b]{2}{*}{$p$} & \multirow[b]{2}{*}{$d$} \\
\hline & $M$ & $S D$ & $M$ & $S D$ & & & \\
\hline Negative emotions & 0.663 & 0.125 & 0.698 & 0.125 & -1.369 & .077 & 0.218 \\
\hline Neutral emotions & 0.682 & 0.167 & 0.718 & 0.158 & -1.781 & .173 & 0.283 \\
\hline Positive emotions & 0.679 & 0.181 & 0.740 & 0.154 & -2.259 & .025 & 0.359 \\
\hline Total & 0.672 & 0.109 & 0.714 & 0.09 & -2.620 & .010 & 0.417 \\
\hline
\end{tabular}


Mentalizing based on external features of others

Table 2

Trauma History and Attachment Style of Borderline Personality Disorder (BPD) Patients and Healthy Control Participants

\begin{tabular}{|c|c|c|c|c|c|c|c|}
\hline & \multicolumn{2}{|c|}{$\mathrm{BPD}(n=79)$} & \multicolumn{2}{|c|}{ Healthy controls $(n=79)$} & \multirow[b]{2}{*}{$t$} & \multirow[b]{2}{*}{$p$} & \multirow[b]{2}{*}{$d$} \\
\hline & $M$ & $S D$ & $M$ & $S D$ & & & \\
\hline Total trauma & 57.30 & 19.06 & 33.29 & 8.62 & 10.025 & .000 & 1.595 \\
\hline Physical abuse & 8.42 & 5.00 & 5.32 & 1.03 & 5.395 & .000 & 0.858 \\
\hline Sexual abuse & 8.03 & 4.44 & 5.29 & 1.43 & 5.209 & .000 & 0.829 \\
\hline Emotional abuse & 14.16 & 5.78 & 7.57 & 2.90 & 9.061 & .000 & 1.442 \\
\hline Physical neglect & 10.11 & 4.74 & 5.96 & 1.72 & 7.323 & .000 & 1.165 \\
\hline Emotional & 16.68 & 5.14 & 9.15 & 3.57 & 10.700 & .000 & 1.702 \\
\hline \multicolumn{8}{|l|}{ neglect } \\
\hline \multicolumn{8}{|l|}{ Attachment } \\
\hline Anxious & 4.46 & 1.30 & 2.30 & 0.80 & 12.845 & .000 & 2.044 \\
\hline Avoidant & 3.89 & 1.03 & 2.51 & 0.76 & 9.519 & .000 & 1.515 \\
\hline
\end{tabular}


Mentalizing based on external features of others

Table 3

Regression Analysis of Trauma History and Group Status on Reading the Mind in the Eyes Test Scores

\begin{tabular}{|c|c|c|c|c|}
\hline \multirow[b]{2}{*}{ Variable } & \multicolumn{4}{|c|}{ Accuracy } \\
\hline & $\beta$ & $t$ & $p$ & $R^{2}$ \\
\hline Neutral Emotions & & & & .042 \\
\hline Group & -.006 & -0.490 & .961 & \\
\hline Total trauma & -.001 & -0.006 & .995 & \\
\hline Group $\times$ Total trauma & $-.209 *$ & -1.706 & .090 & \\
\hline Negative Emotions & & & & .013 \\
\hline Group & .143 & 0.207 & .229 & \\
\hline Total trauma & .049 & 0.429 & .668 & \\
\hline Group $\times$ Total trauma & .004 & 0.035 & .972 & \\
\hline Positive Emotions & & & & .041 \\
\hline Group & .109 & 0.933 & .353 & \\
\hline Total trauma & .059 & 0.526 & .600 & \\
\hline Group $\times$ Total trauma & -.151 & -1.237 & .218 & \\
\hline Total Emotions & & & & .057 \\
\hline Group & .110 & 0.941 & .348 & \\
\hline Total trauma & .053 & 0.468 & .641 & \\
\hline Group $\times$ Total trauma & -.185 & -1.523 & .130 & \\
\hline
\end{tabular}


Mentalizing based on external features of others

Table 4

Regression Analysis of Anxious Attachment and Group Status on Reading the Mind in the Eyes Test Scores

\begin{tabular}{|c|c|c|c|c|}
\hline \multirow[b]{2}{*}{ Variable } & \multicolumn{4}{|c|}{ Accuracy } \\
\hline & $\beta$ & $t$ & $p$ & $R^{2}$ \\
\hline Neutral Emotions & & & & .033 \\
\hline Group & .114 & 0.946 & .346 & \\
\hline Anxious Attachment & .133 & 0.969 & .334 & \\
\hline Group $\times$ Anxious Attachment & -.180 & -1.379 & .170 & \\
\hline Negative Emotions & & & & .027 \\
\hline Group & $.247 * *$ & 2.062 & .041 & \\
\hline Anxious Attachment & .093 & 0.688 & .493 & \\
\hline Group $\times$ Anxious Attachment & .104 & 0.794 & .428 & \\
\hline Positive Emotions & & & & .036 \\
\hline Group & .112 & 0.941 & .348 & \\
\hline Anxious Attachment & -.024 & -0.176 & .860 & \\
\hline Group $\times$ Anxious Attachment & -.071 & -0.545 & .587 & \\
\hline Total Emotions & & & & .047 \\
\hline Group & $.226^{*}$ & 1.892 & .060 & \\
\hline Anxious Attachment & .114 & 0.837 & .404 & \\
\hline Group $\times$ Anxious Attachment & -.091 & -0.700 & .485 & \\
\hline
\end{tabular}


Mentalizing based on external features of others

Table 5

Regression Analysis of Avoidant Attachment and Group Status on Reading the Mind in the Eyes Test Scores

\begin{tabular}{|c|c|c|c|c|}
\hline \multirow[b]{2}{*}{ Variable } & \multicolumn{4}{|c|}{ Accuracy } \\
\hline & $\beta$ & $t$ & $p$ & $R^{2}$ \\
\hline Neutral Emotions & & & & .073 \\
\hline Group & -.160 & -0.154 & .877 & \\
\hline Avoidant Attachment & -.062 & -0.500 & .618 & \\
\hline Group $\times$ Avoidant Attachment & $-.231 * *$ & -1.994 & .048 & \\
\hline Negative Emotions & & & & .014 \\
\hline Group & .125 & 1.216 & .226 & \\
\hline Avoidant Attachment & .004 & 0.031 & .976 & \\
\hline Group $\times$ Avoidant Attachment & .009 & 0.076 & .940 & \\
\hline Positive Emotions & & & & .064 \\
\hline Group & .043 & 0.430 & .668 & \\
\hline Avoidant Attachment & -.123 & -1.002 & .318 & \\
\hline Group $\times$ Avoidant Attachment & -.118 & -1.024 & .308 & \\
\hline Total Emotions & & & & .085 \\
\hline Group & .067 & 0.674 & .502 & \\
\hline Avoidant Attachment & -.080 & -0.651 & .516 & \\
\hline Group $\times$ Avoidant Attachment & -.182 & -1.586 & .115 & \\
\hline
\end{tabular}




\section{decisive amused}

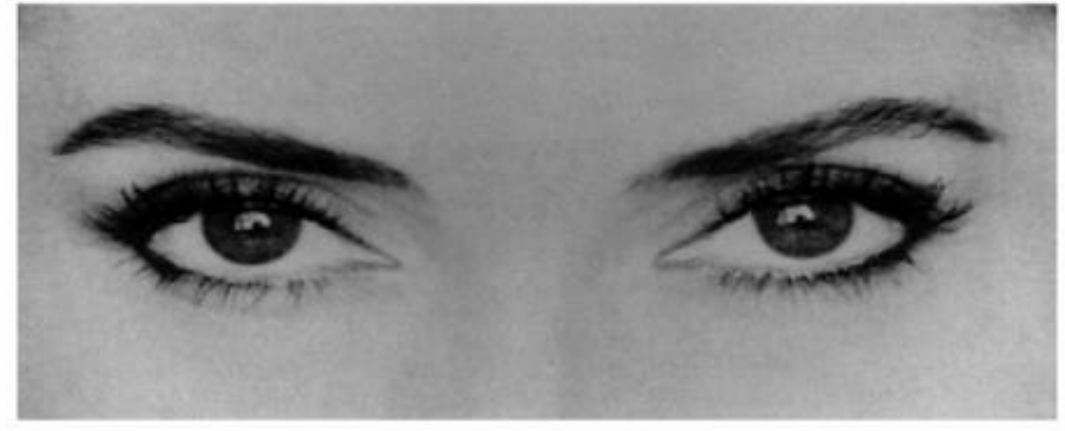

aghast

bored

Figure 1. An example of a (female) stimulus in the Reading the Mind in the Eyes Test: In the revised edition the correct answer is "decisive" (Baron-Cohen, Wheelwright, Hill, Raste, \& Plumb, 2001). 
Mentalizing based on external features of others

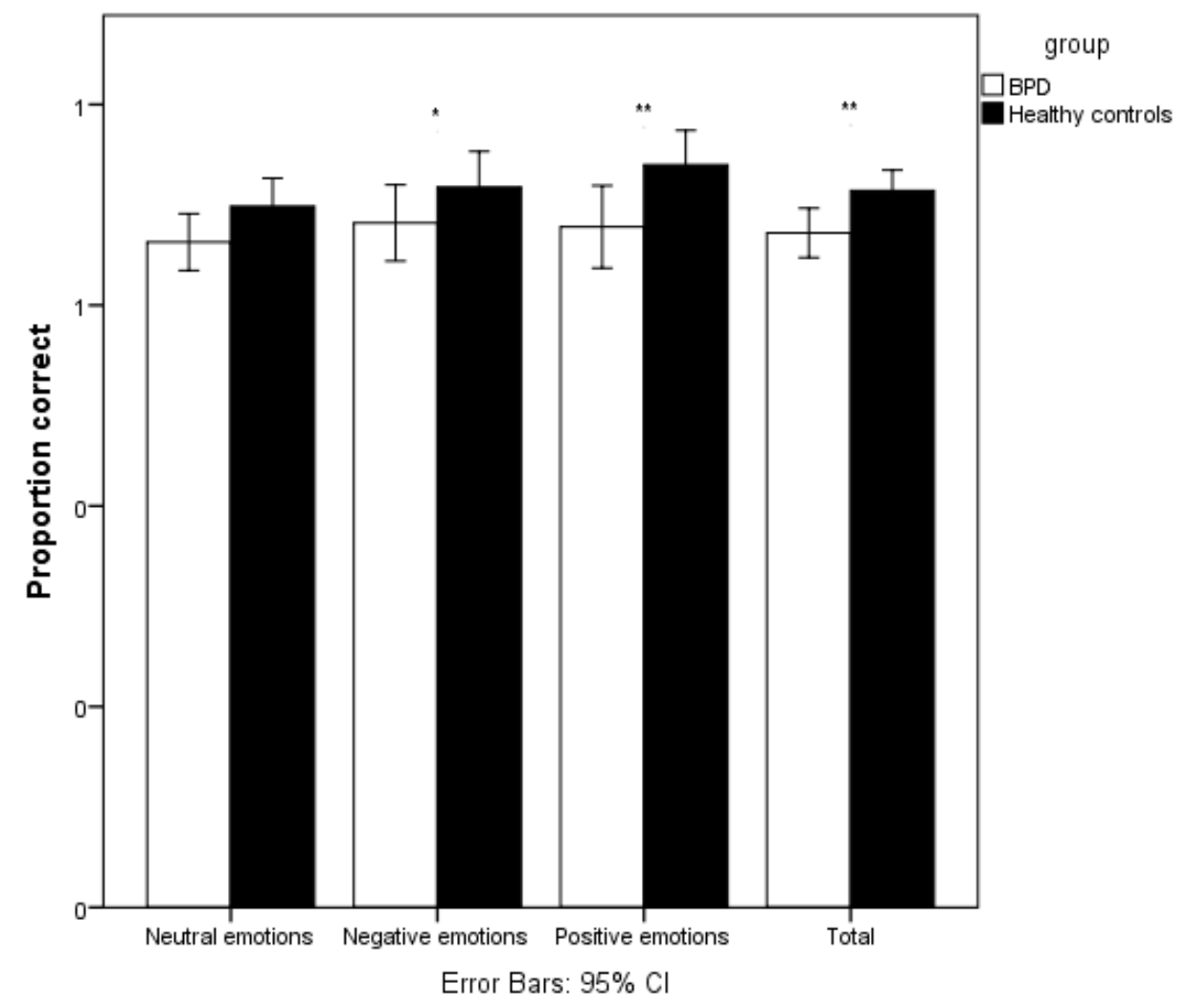

Figure 2. Comparison between BPD and control group on the total Reading the Mind in the Eyes Test score, and scores for positive, negative, and neutral emotions. Significant group difference: ${ }^{*} p<.05, * * p<.1$. 
Mentalizing based on external features of others

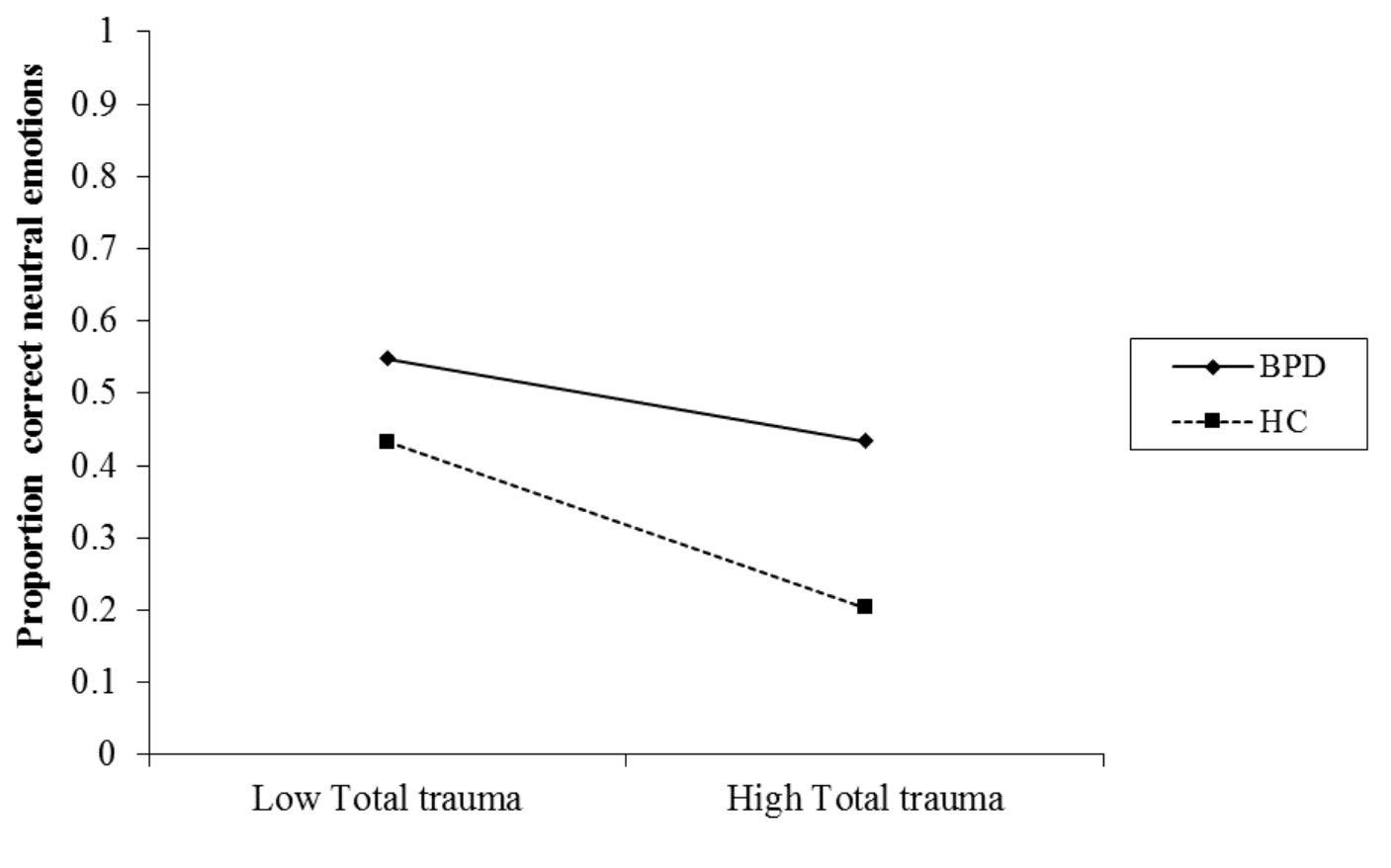

Figure 3. Interaction between trauma history and group status on the accuracy of recognizing neutral emotions.

Note. BPD, Borderline Personality Disorder group; HC, healthy controls. 
Mentalizing based on external features of others

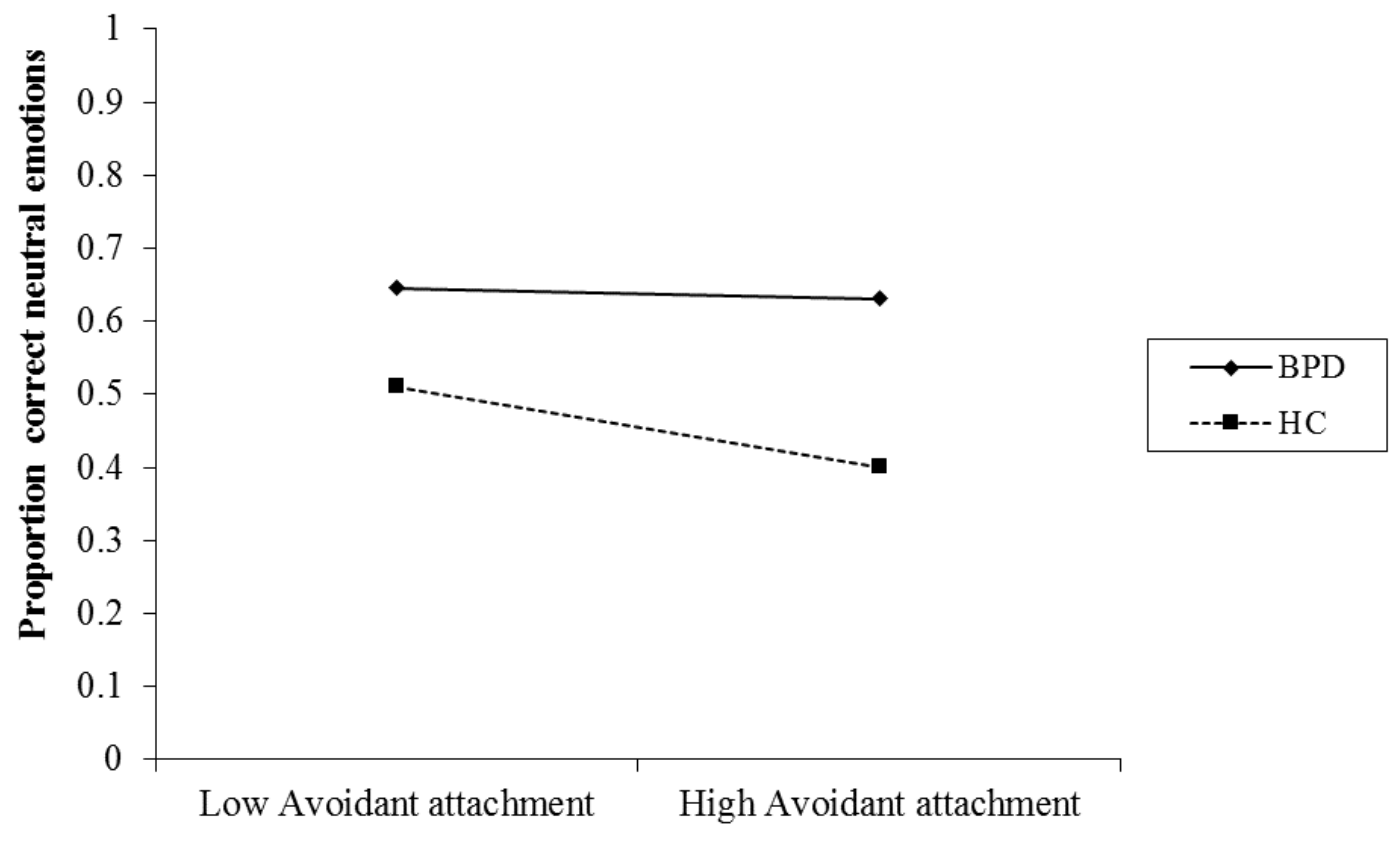

Figure 4. Interaction between avoidant attachment and group status on the accuracy of recognizing neutral emotions.

Note. BPD, Borderline Personality Disorder group; HC, healthy controls. 